\title{
Phase 2 of the Coronavirus Pandemic in Urology: Ramping Up Surgical Caseload and Resident Training while COVID-19 Infections Decrease
}

\author{
Hendrik Borgmann Katharina Boehm Maximilian Peter Brandt \\ Mohammed M. Kamal Rene Mager Thomas Höfner Igor Tsaur \\ Axel Haferkamp \\ Department of Urology, University Medical Center, Johannes Gutenberg University, Mainz, Germany
}

\section{Dear Editor,}

The coronavirus disease 2019 (COVID-19) pandemic is disrupting urology healthcare worldwide [1]. Constraints on healthcare resources have led to prioritization strategies aiming to minimize patient harm during a time of reduced surgical caseload capacity [2]. In phase 2 of the pandemic, we experienced in our department decreasing COVID-19 in-hospital caseload over time, allowing for increasing surgical caseload for urology consultants and residents. Here, we aimed to investigate the course of urological surgical caseload in our department before and during the COVID-19 pandemic and its relationship to local COVID-19 infection load.

We performed a retrospective analysis of all scheduled urology surgeries under general anaesthesia performed in our department during a time frame of 12 weeks between February 25, 2020, and May 15, 2020. To track the overall surgical caseload, we recorded the number of surgeries performed overall in the urology department. To track the surgical training of urology residents, we recorded the number of surgeries performed by urology residents. Simultaneously, the number of COVID-19-positive tested in-hospital patients was recorded. The 12-week time span was divided into 4 time periods of each successive 3 weeks: pre-COVID-19 time, lockdown time, resumption time, and back-to-normal time. Low prioritization pressure leads to cancellations of surgeries with low priority ac-

karger@karger.com

(c) 2021 S. Karger AG, Basel

www.karger.com/uin

Karger! cording to the 4-tired surgery prioritization list by the German Society of Urology at the beginning of the lockdown time [3], while all oncological cases could be continued irrespective of cancer entity or risk. At the beginning of the resumption time, stone surgery was resumed. At the beginning of the back-to-normal time, all surgeries were resumed.

During 56 working days, we performed 537 surgeries under general anaesthesia, of which 162 (30\%) were performed by urology residents. The median number of surgeries per day was 10 overall and 3 for urology residents. In-hospital COVID-19 caseload increased until a peak of 24 cases, remained stable, and decreased thereafter (median: 17.5; range: 7-24 cases). Overall and residents' surgical caseload, respectively, was 164 and 47 in the preCOVID-19 time, decreased to 103 and 27 in the lockdown time, increased to 117 and 37 in the resumption time, and increased again to 153 and 51 in the back-tonormal time. One COVID-19 infection occurred in inhospital urology patients during the 12 -week time frame $(0.2 \%)$. Figure 1 shows an inverse relation between the COVID-19 in-hospital caseload and the urological surgical caseload for both overall number of surgeries and surgeries performed by residents. Ramping up of surgical training for residents is particularly important since slowdown of learning and psychological impacts have been reported $[4,5]$. 
Fig. 1. Inverse relation between COVID-19 in-hospital caseload and surgical caseload and resident training during different time spans before and during the COVID-19 pandemic. COVID-19, coronavirus disease 2019.
Inverse relation between COVID-19 in-hospital caseload and surgery caseload and resident training

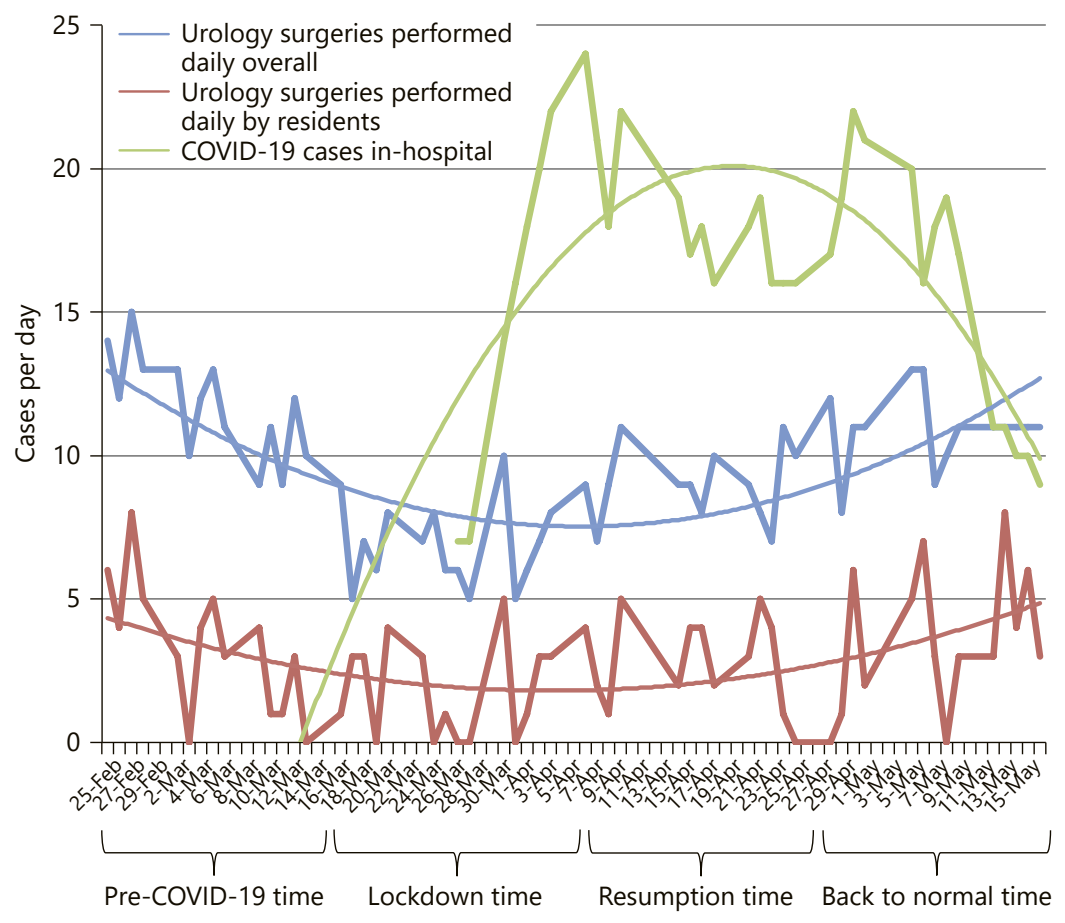

Our single-institution data show that urological surgical caseload and resident training can be ramped up with decreasing COVID-19 infections, aiming to ensure perpetuation of adequate treatment for both oncological and non-oncological urology patients. Limitations include the retrospective study design and lack of data on patientrelated outcomes. However, our data show that the burden of surgical caseload deferred due to COVID-19 can be worked off as COVID-19 infections decrease, aiming to minimize the collateral damage of morbimortality in urology patients [6].

\section{Conflict of Interest Statement}

The authors have no potential conflict of interest.

\section{Funding Sources}

The authors did not receive any funding.

\section{Author Contributions}

Project development: H.B. and A.H. Data collection/management: all authors. Data analysis: H.B. Manuscript writing/editing: all authors.

\section{References}

1 Chan VW, Chiu PK, Yee CH, Yuan Y, Ng CF, Teoh JY. A systematic review on COVID-19: urological manifestations, viral RNA detection and special considerations in urological conditions. World J Urol. 2020 [Online ahead of print].

2 Ribal MJ, Cornford P, Briganti A, Knoll T, Gravas S, Babjuk M, et al. European association of urology guidelines office rapid reaction group: an organisation-wide collaborative effort to adapt the European association of urology guidelines recommendations to the coronavirus disease 2019 era. Eur Urol. 2020 Jul;78(1):21-8.

3 Kriegmair MC, Kowalewski KF, Lange B, Heininger A, Speck T, Haas H, et al. [Urology in the corona-virus pandemic-a guideline 4/20]. Urologe A. 2020;59(4):442-9.

4 Abdessater M, Roupret M, Misrai V, Pinar U, Matillon X, Gondran-Tellier B, et al. COVID-19 outbreak situation and its psychological impact among surgeons in training in France. World J Urol. 2020 Apr 24:1-2.
5 Porpiglia F, Checcucci E, Amparore D, Verri $\mathrm{P}$, Campi R, Claps F, et al. Slowdown of urology residents' learning curve during the COVID-19 emergency. BJU Int. 2020 Jun;125(6): E15-E17.

6 Porreca A, Colicchia M, D'Agostino D, Amenta M, Corsaro A, Zaramella S, et al. Urology in the time of coronavirus: reduced access to urgent and emergent urological care during the coronavirus disease 2019 outbreak in Italy. Urol Int. 2020:1-6. 